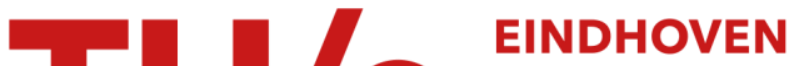 UNIVERSITY OF TECHNOLOGY
}

\section{The effect of the gas void distribution on the ohmic resistance during water electrolysis}

\section{Citation for published version (APA):}

Bongenaar-Schlenter, B. E., Janssen, L. J. J., Stralen, van, S. J. D., \& Barendrecht, E. (1985). The effect of the gas void distribution on the ohmic resistance during water electrolysis. Journal of Applied Electrochemistry, 15(4), 537-548. https://doi.org/10.1007/BF01059295

DOI:

10.1007/BF01059295

Document status and date:

Published: 01/01/1985

\section{Document Version:}

Publisher's PDF, also known as Version of Record (includes final page, issue and volume numbers)

\section{Please check the document version of this publication:}

- A submitted manuscript is the version of the article upon submission and before peer-review. There can be important differences between the submitted version and the official published version of record. People interested in the research are advised to contact the author for the final version of the publication, or visit the $\mathrm{DOI}$ to the publisher's website.

- The final author version and the galley proof are versions of the publication after peer review.

- The final published version features the final layout of the paper including the volume, issue and page numbers.

Link to publication

\section{General rights}

Copyright and moral rights for the publications made accessible in the public portal are retained by the authors and/or other copyright owners and it is a condition of accessing publications that users recognise and abide by the legal requirements associated with these rights.

- Users may download and print one copy of any publication from the public portal for the purpose of private study or research.

- You may not further distribute the material or use it for any profit-making activity or commercial gain

- You may freely distribute the URL identifying the publication in the public portal.

If the publication is distributed under the terms of Article 25fa of the Dutch Copyright Act, indicated by the "Taverne" license above, please follow below link for the End User Agreement:

www.tue.nl/taverne

Take down policy

If you believe that this document breaches copyright please contact us at:

openaccess@tue.nl

providing details and we will investigate your claim. 


\title{
The effect of the gas void distribution on the ohmic resistance during water electrolytes*
}

\author{
B. E. BONGENAAR-SCHLENTER, L. J. J. JANSSEN, S. J. D. VAN STRALEN, \\ E. BARENDRECHT
}

Eindhoven University of Technology, PO Box 513, 5600 MB Eindhoven, The Netherlands

Received 24 December 1984

Due to the presence of gas bubbles on the electrode surface and in the interelectrode gap during water electrolysis, the ohmic resistance in the cell increases. The main aim of this investigation is to obtain insight into the effect of the gas void distribution on the ohmic resistance in the electrolysis cell. The gas void distribution perpendicular to the electrode surface has been determined at various current densities, solution flow velocities and heights in the cell, taking high speed motion pictures. From these measurements it follows that two bubble layers can be distinguished. The current density distribution and the ohmic resistance in the electrolysis cell have been determined using a segmented nickel electrode. The current density decreases at increasing height in the cell. The effect is more pronounced at low solution flow velocities and high current densities. A new model to calculate the ohmic resistance in the cell is proposed.

\section{Nomenclature}

$A_{l} \quad$ electrolyte area $\left(\mathrm{m}^{2}\right)$

c constant (-)

$d_{\mathrm{wm}}$ distance between the working electrode and the diaphragm resp. the tip of the Luggin capillary $(\mathrm{m})$

$E \quad$ voltage of an operating cell (V)

$f$ gas void fraction $(-)$

$F \quad$ Faraday constant $(\mathrm{C} / \mathrm{mol})$

$f_{0} \quad$ gas void fraction at the electrode surface (-)

$f_{\mathrm{b}}$ gas void fraction in the bulk electrolyte (-)

$h$ height from the bottom of the working electrode $(\mathrm{m})$

$h_{\mathrm{r}} \quad$ reference height $(=1 \mathrm{~cm})(\mathrm{m})$

$H$ total height of the electrode (m)

$i$ current density $\left(\mathrm{A} \mathrm{m}^{-2}\right)$

$i_{\text {av }}$ average current density $\left(\mathrm{A} \mathrm{m}^{-2}\right)$

$i_{\mathrm{r}} \quad$ reference current density $\left(=1 \mathrm{kA} \mathrm{m}^{-2}\right)$ $\left(\mathrm{A} \mathrm{m}^{-2}\right)$

\section{Introduction}

During alkaline water electrolysis, oxygen and hydrogen bubbles, which are evolved on the elec-
$R \quad$ resistance $(\Omega)$

$R^{\prime} \quad$ specific resistance $\left(\Omega_{\mathrm{m}}\right)$

$R^{\prime \prime} \quad$ unit surface resistance $\left(\Omega \mathrm{m}^{2}\right)$

$R_{1} \quad$ resistance of the first bubble layer $(\Omega)$

$R_{2}$ resistance of the second bubble layer $(\Omega)$

$R_{\text {cell }}$ ohmic resistance in the cell $(\Omega)$

$R_{\mathrm{b}} \quad$ bubble radius (m)

$s_{l} \quad$ degree of screening by bubbles in the electrolyte $(-)$

$v_{l} \quad$ liquid flow velocity $\left(\mathrm{ms}^{-1}\right)$

$v_{1, r}$ reference liquid flow velocity $\left(=1 \mathrm{~m} \mathrm{~s}^{-1}\right)$ $\left(\mathrm{m} \mathrm{s}^{-1}\right)$

$V_{\mathrm{M}}$ molar gas volume $\left(\mathrm{m}^{3} \mathrm{~mol}^{-1}\right)$

$w \quad$ width of the electrode $(\mathrm{m})$

$x$ distance from the electrode surface $(\mathrm{m})$

$\delta \quad$ thickness of the bubble layer adjacent to the electrode $(\mathrm{m})$

$\psi \quad$ number of bubbles generated per unit surface area and unit time $\left(\mathrm{m}^{-2} \mathrm{~s}^{-1}\right)$

trodes, cause an increase in the ohmic resistance in the electrolysis cell. Consequently, the energy efficiency of the electrolysis process decreases. The current distribution in a vertical cell is also affected

\footnotetext{
* Paper presented at the International Meeting on Electrolytic Bubbles organised by the Electrochemical Technology Group of the Society of Chemical Industry, and held at Imperial College, London, 13-14 September 1984.
} 
by the evolved bubbles. The gas void fraction in the cell increases with increasing height and consequently, the current density is expected to decrease with increasing height. Although Tobias [1] published a theoretical approach to the current density distribution in a vertical electrolysis cell in 1959, so far hardly any experimental data on this topic have been reported.

In the past, several models have been proposed [1-6] for calculation of the current distribution and ohmic resistance in electrolysis cells. Except for the models of Vogt [5] and Sillen [6] these models assume a uniform gas fraction distribution in the interelectrode gap, thus neglecting the fact that in the vicinity of the bubble source, the electrode, the gas fraction will be higher than in the bulk electrolyte. According to Bruggeman's equation, the effect of the bubbles in this region on the effective resistance of the electrolyte will be substantially higher. Since in the models of Vogt and Sillen the thickness of the bubble layer adjacent to the electrode is confined to only one average bubble diameter, the contribution of this layer to the total resistance is probably still underestimated.

In this paper experimental data on bubble distributions and current density distributions in an electrolysis cell are presented. A new model for calculation of the ohmic resistance in the electrolysis cell is proposed.

\section{Experimental details}

\subsection{Bubble distribution}

The experimental set-up for bubble measurements is shown in Fig. 1. The electrolysis cell consists of two sections. One section is made of transparent acrylate resin and contains the counter electrode (perforated nickel plate, $50 \times 2 \mathrm{~cm}^{2}$ ), while the other section (stainless steel setting) incorporates the working electrode.

The working electrode consists of a glass plate on which a thin gold layer is deposited. The glass plate is glued in the stainless steel setting and serves as the backwall of the working electrode section. The sections are separated by a transparent Nafion (Du Pont) membrane. The counter electrode is placed against the membrane, while the distance between the working electrode and the membrane is $6 \mathrm{~mm}$. The electrolysis cell is connected to a circuit for forced flow. Details of this circuit are given in [7,8].

The bubble density and velocity distributions in the electrolysis cell are recorded using a high speed film camera. To get optimally contrasted bubbles on the pictures, the light source, for which a mercury arc lamp is used, is placed at the opposite side of the electrolysis cell. A positive lens is used to focus the light beam in the recording area.

Because of the small sizes of the bubbles (10-

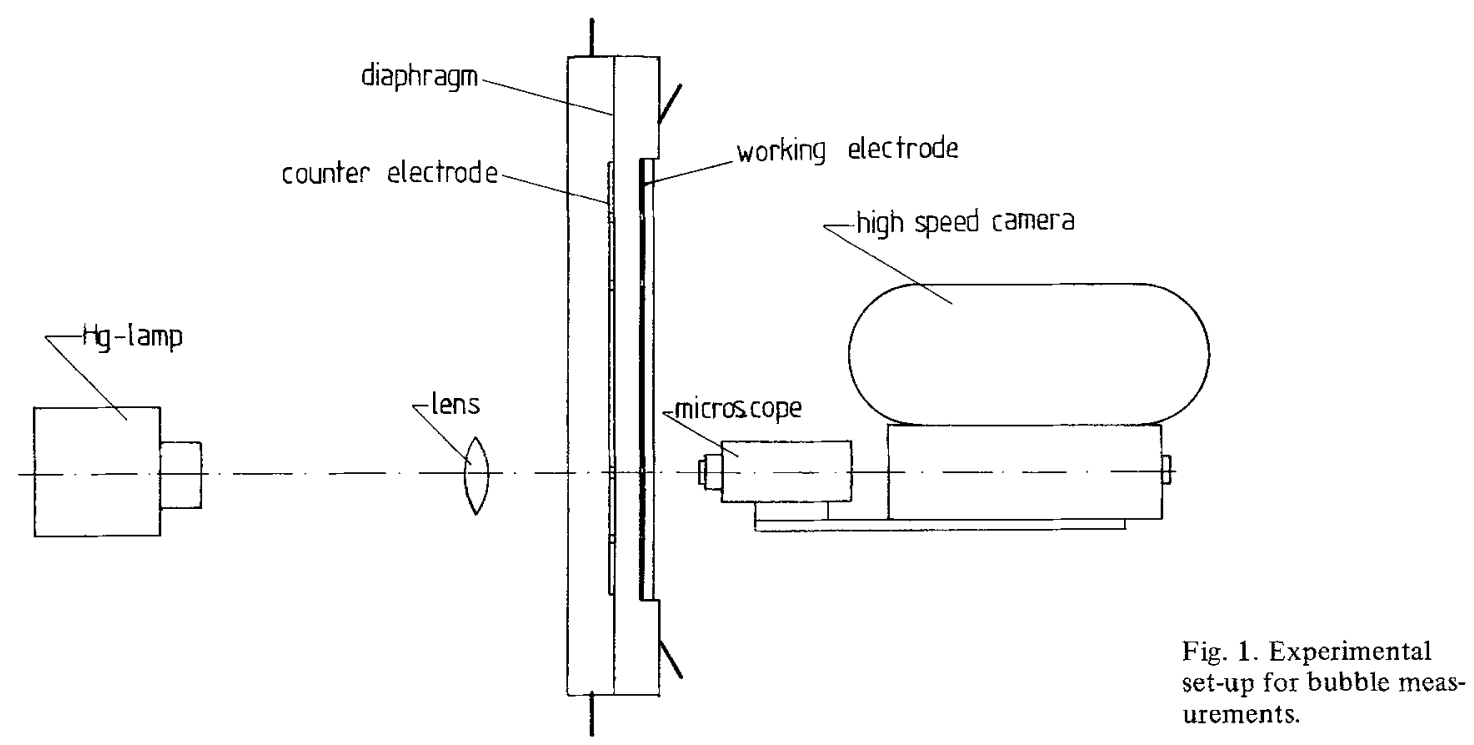


$100 \mu \mathrm{m})$ a microscope has to be used. The magnification factor is determined by the microscope objective and its distance to the camera (no ocular is used). Its value is established by measuring a recorded scale of one millimeter which is divided in 100 equal parts; it is found to be approximately 300. To obtain sharp pictures, picture frequencies up to 8000 frames $^{-1}$ have to be used when forced flow up to $0.75 \mathrm{~m} \mathrm{~s}^{-1}$ is applied. Light marks on the edge of the film, initiated by the camera every millisecond, indicate the framing frequency.

Before a series of experiments, the microscope is focused on the surface of the gold electrode. The camera and the microscope can be translated simultaneously maintaining a constant magnification factor. From the displacement of the camera the focus point in the electrolysis cell is determined, taking into account the difference in refractive index between the electrolyte and air.

Unless otherwise mentioned, the experiments have been carried out galvanostatically with a hydrogen evolving gold electrode at atmospheric pressure, in $1 \mathrm{M} \mathrm{KOH}$ solution at $303 \mathrm{~K}$, at a current density of $0.75 \mathrm{kA} \mathrm{m}^{-2}$ and with an applied flow velocity of $0.3 \mathrm{~m} \mathrm{~s}^{-1}$. The current density is calculated by dividing the total current by the active geometrical surface area of the working electrode. The solution flow velocity is calculated by dividing the volumetric flow rate of the solution by the cross-sectional area of the compartment diminished by the crosssectional area of the electrode in the compartment.

Only hydrogen bubbles have been studied since the thin gold layer crumbles from the glass plate with oxygen evolution. The bubbles on a frame are measured on the screen of a motion analyser. The data are recorded on paper-tape and handled by computer. Since one frame only represents the bubble situation at a distinct time, and fluctuations, on a small time scale, in the bubble behaviour may occur, it is likely that the bubble situation on one frame does not represent the average bubble situation. Therefore bubble quantities are averaged over approximately 10 randomly taken frames for each experimental condition. In this way representative results are obtained.

\subsection{Current density distribution and ohmic potential drop}

The electrolysis cell used for the determination of current density distribution and ohmic resistance measurements consists of stainless steel and is divided into two parts, the working and the counter electrode compartment, by an asbestos diaphragm. The counter electrode is a nickel Venetian blind electrode of $50 \times 2 \mathrm{~cm}^{2}$ and is placed against the asbestos diaphragm. Details of this electrode are given in $[7,8]$. The working electrode (cf. Fig. 2) consists of 20 nickel plates of $2.30 \times 1.85 \mathrm{~cm}^{2}$ embedded in an acrilate plate. To each nickel plate two wires are attached, namely, a tinned copper wire used as a current feeder and a nickel wire for 'currentless' potential measurements. The working electrode is placed against the backwall of the working electrode surface and the diaphragm.

For the electrode consisting of 20 separate electrode segments to resemble one flat equipotential plate electrode, it is of utmost importance to keep all the electrode segments at the same potential. For this purpose a special potentiostat has been designed. The current through each segment is adjusted so that the potential differences between the segments and the counter electrode all equal a set value. The current through each segment is determined by measuring the potential drop over a calibrated resistance of $0.1 \Omega$. The maximum possible current through a segment is restricted to approximately $6 \mathrm{~A}$.

Five glass Luggin capillaries, with an outer tipdiameter of approximately $0.8 \mathrm{~mm}$ enter the cell at various heights through the backwall of the counter electrode compartment and protrude through little holes in the middle of the counter electrode and the diaphragm. The capillaries are situated at $5,15,25,35$ and $45 \mathrm{~cm}$ from the lower edge of the working electrode. The distance from the tips of the Luggin capillaries to the working electrode can be varied and measured by means of micro-screws. Each capillary is connected to a reference electrode consisting of $\mathrm{Hg} / \mathrm{HgO} / \mathrm{KOH}$.

The ohmic potential drops between various segments of the working electrode and the Luggin capillaries are measured simultaneously, using the current interruptor technique. The current through each segment is interrupted simultaneously by 


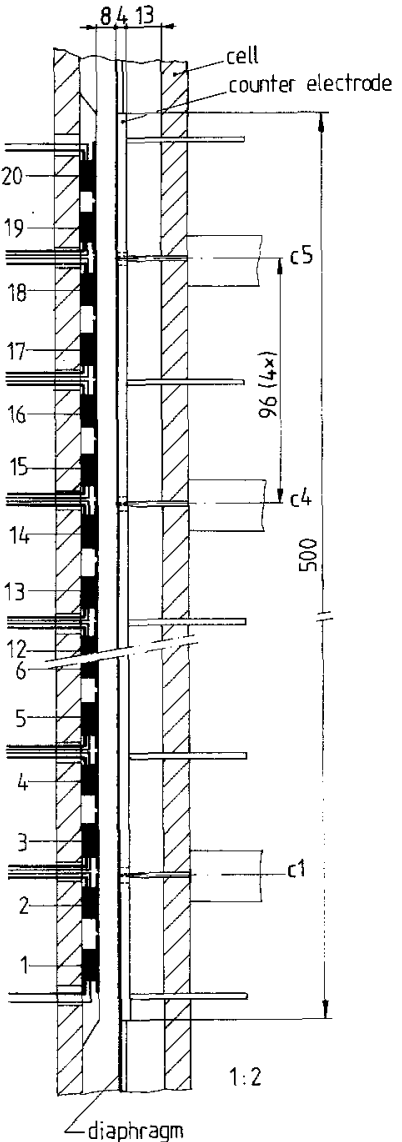

Fig. 2. Schematic outline of the segmented nickel electrode.

electronic switches and the potential drops are recorded by a four channel transient recorder and printed.

Unless otherwise stated, the experiments have been carried out potentiostatically at atmospheric pressure in a $30 \mathrm{wt} \% \mathrm{KOH}$ solution at $313 \mathrm{~K}$. Hydrogen as well as oxygen evolution has been studied at various current densities and solution flow velocities. The distances between the tips of the Luggin capillaries and the working electrode equal $4 \mathrm{~mm}$.

\section{Results}

\subsection{Bubble distribution in the electrolyte}

3.1.1. Introduction. The transparency of the gold electrode used for bubble distribution experiments was only $1-2 \%$. Therefore, the illumination of the bubbles in the electrolyte was insufficient to take high speed motion pictures. To determine the bubble distribution in the electrolyte, the thin gold layer with a thickness of about $80 \mathrm{~nm}$ was removed from the glass support at four spots, thus creating small windows through which the bubbles in the electrolyte could be studied.

Due to the large magnification used, the depth of field is limited. Only bubbles with sharply defined outlines (located in a thin layer of electrolyte of approximately $100 \mu \mathrm{m}$ ) are measured. From the experiments the degree of screening in the electrolyte has been determined, (i.e. the fraction of the electrolyte area covered by the projection of the bubbles).

$$
s_{l}=\left(\sum_{i=1}^{N} \pi R_{i}^{2}\right) / c A_{l}
$$

The proportionality factor, $c$, accounts for the depth of field of the optical system.

\subsubsection{Effect of current density. The effect of} current density on the degree of screening in the electrolyte, $s_{l}$, is illustrated in Fig. 3 at three current densities namely, $0.15,0.75$ and $1.5 \mathrm{kA} \mathrm{m}^{-2}$ at a solution flow velocity of $0.3 \mathrm{~m} \mathrm{~s}^{-1}$ and a height of approximately $7 \mathrm{~cm}$ from the bottom of the electrode. The figure shows that two layers may be distinguished in the electrolyte. The first layer adjacent to the electrode, exhibits a sharp decrease in the degree of screening with increasing distance from the electrode surface. In the second layer, $s_{l}$ decreases only slightly with increasing distance from the electrode.

The width of the first layer is estimated by drawing by hand two straight lines, approximating the screening in the respective layers. The intersection of these lines marks the transition of

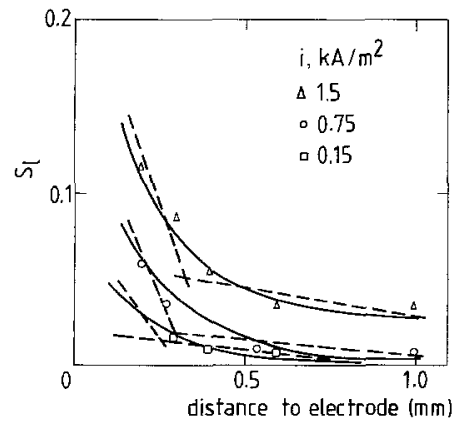

Fig. 3. The screening in the electrolyte as a function of the distance to the electrode surface. $v_{l}=0.3 \mathrm{~m} \mathrm{~s}^{-1}, h=7 \mathrm{~cm}$. 


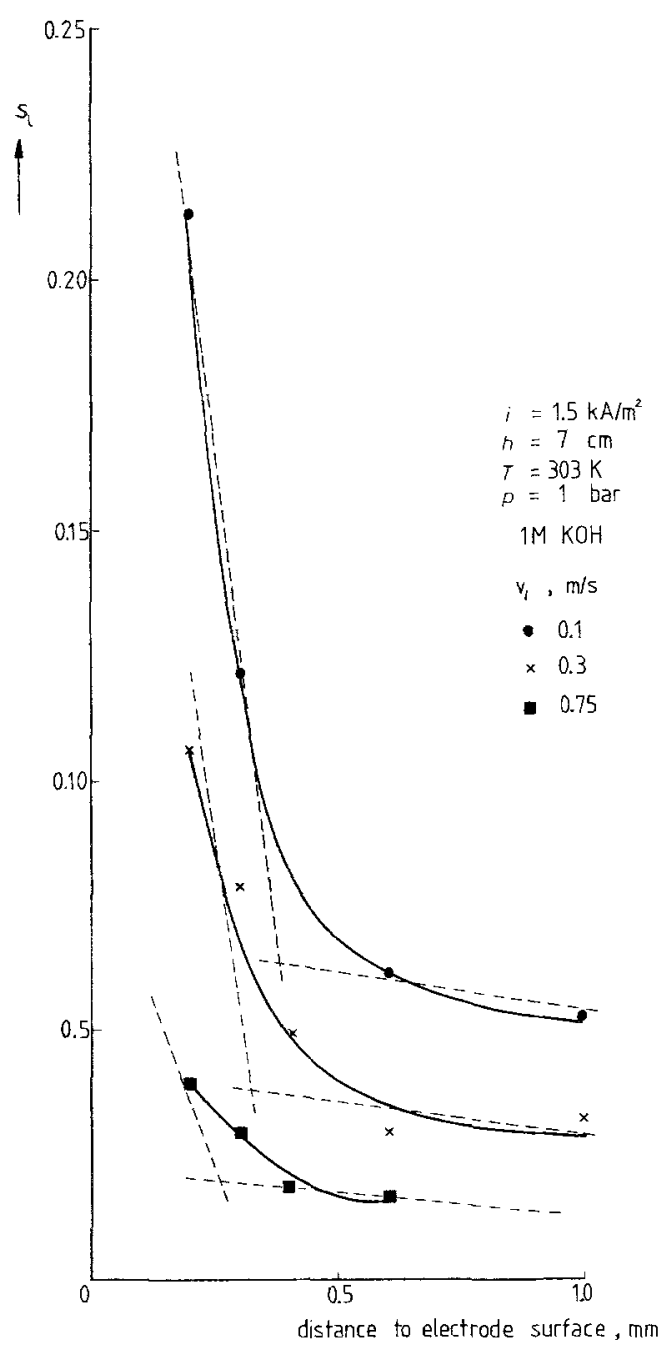

Fig. 4. The degree of screening as a function of distance to the electrode surface at various solution flow velocities.

the first to the second layer in the figure. A plot of the width of the first layer as a function of current density on a double logarithmic scale shows a straight line with a slope of approximately 0.1 , indicating a slight dependence of $\delta$ on $i$. The width of the layer adjacent to the electrode in dependence on current density can therefore be approximated by:

$$
\delta \sim i^{0.1}
$$

\subsubsection{Effect of solution flow velocity. The effect} of solution flow velocity on the degree of screening in the electrolyte is given in Fig. 4. From this figure it follows that $s_{l}$ increases at decreasing solution flow velocity. The width of the first layer of electrolyte adjacent to the electrode is estimated as described in the previous section and depends on the flow velocity. From a plot of $\delta$ against $\nu_{l}$ on a double logarithmic scale the following expression for the dependence of $\delta$ on $v_{l}$ is obtained:

$$
\delta \sim v_{l}^{-0.2}
$$

3.1.4. Effect of height. In Fig. 5 the degree of screening in the electrolyte is plotted versus the distance from the electrode surface at three heights, $h$, in the electrolysis cell namely 7,15 and $33 \mathrm{~cm}$ from the bottom of the electrode. As is to be expected, the degree of screening in the electrolyte increases with increasing height in the cell. The width of the layer adjacent to the electrode, where the degree of screening decreases strongly, depends on the height in the electrolysis cell. A plot of $\delta$ versus $h$ on a double logarithmic scale shows a straight line with a slope of 0.3 . The dependence of $\delta$ on $h$ can therefore be estimated by:

$$
\delta \sim h^{0.3}
$$

\subsubsection{Conclusions. Summarizing the previous} results, the dependence of $\delta$ on current density, solution flow velocity and height is obtained from a combination of Equations 2-4 and may in principle be represented by:

$$
\delta \sim i^{c_{1}} v_{l}^{c_{2}} h^{c_{3}}
$$

The proportionality factor and the respective exponents probably depend on the cell geometry and the nature of the solution flow. In the present cell geometry the thickness of the first bubble layer adjacent to the electrode surface can approximately be represented by:

$$
\delta / \delta_{\mathbf{r}}=\left(i / i_{\mathbf{r}}\right)^{0.1}\left(v_{l} / v_{l, r}\right)^{-0.2}\left(h / h_{\mathbf{r}}\right)^{0.3}
$$

The value of $\delta_{\mathrm{r}}$ is determined, taking as a reference situation $i=0.75 \mathrm{kA} \mathrm{m}^{-2}, v_{l}=0.3 \mathrm{~m} \mathrm{~s}^{-1}, h=7 \mathrm{~cm}$ and $\delta=0.30 \mathrm{~mm}$ to be $0.14 \mathrm{~mm}$. It should, however, be noted that this is only a rough approximation. The relative experimental uncertainty in the screening values is of the order of $10 \%$, and the way in which $\delta$ has been estimated is questionable. Therefore, Equation 6 can only be considered as giving an indication of the effect of the respective parameters on $\delta$.

\subsection{Current density distribution}

3.2.I. Effect of current. The effect of the current through the electrolysis cell on the current density 


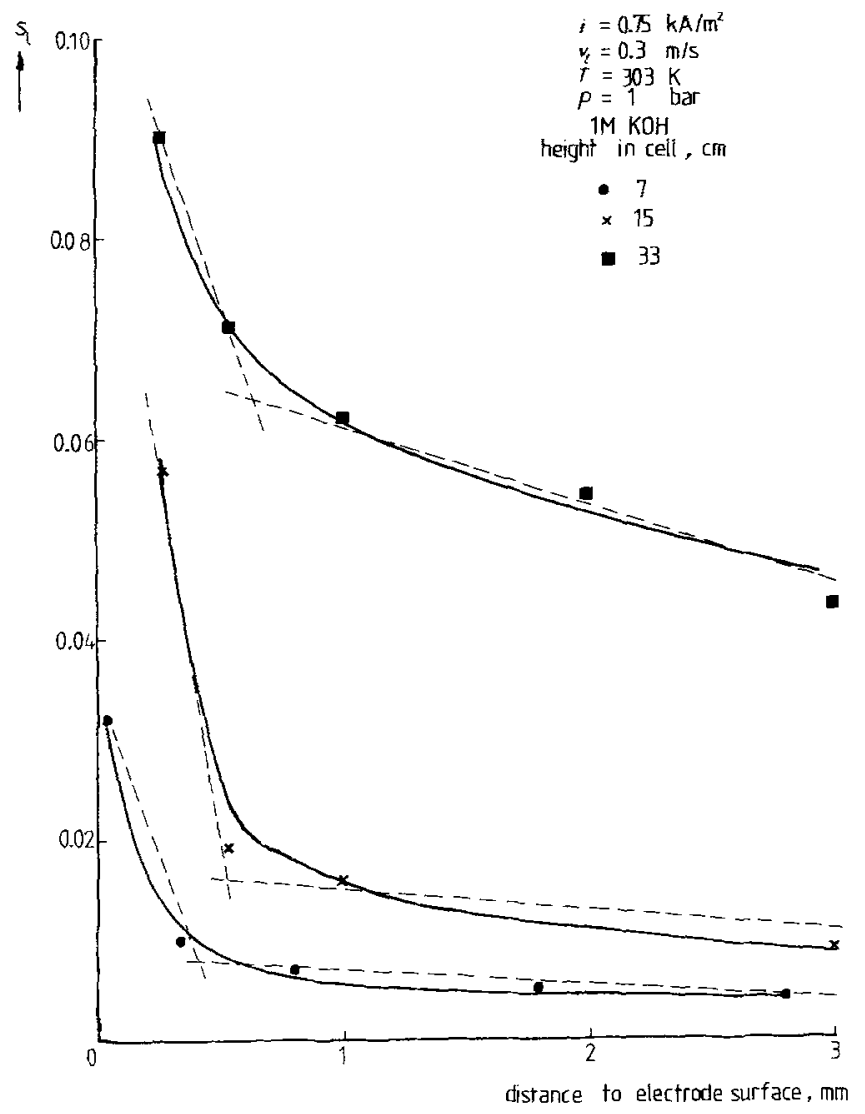

Fig. 5. The degree of screening as a function of distance to the electrode surface at various heights in the cell.

distribution over the working electrode is illustrated in Fig. 6 for oxygen and hydrogen evolution at the working electrode at a solution flow velocity of $0.05 \mathrm{~m} \mathrm{~s}^{-1}$. The current density decreases with increasing height in the electrolysis cell. The effect is more pronounced at high current densities when the gas production is high. The relatively high values of the current density for both the top and the bottom segments result from the inhomogeneous primary and secondary current density distribution in a parallel flat plate reactor in which the electrodes do not fully occupy their respective sides of the reactor. The relative difference in the current density, obtained by linear extrapolation, between the bottom and the top of the electrolysis cell is approximately $20 \%$ at an average current density of $8 \mathrm{kA} \mathrm{m}^{-2}$.

\subsubsection{Effect of solution flow velocity. In Fig. 7} the current density distribution over the working electrode for hydrogen evolution at this electrode is shown at various solution flow velocities at a

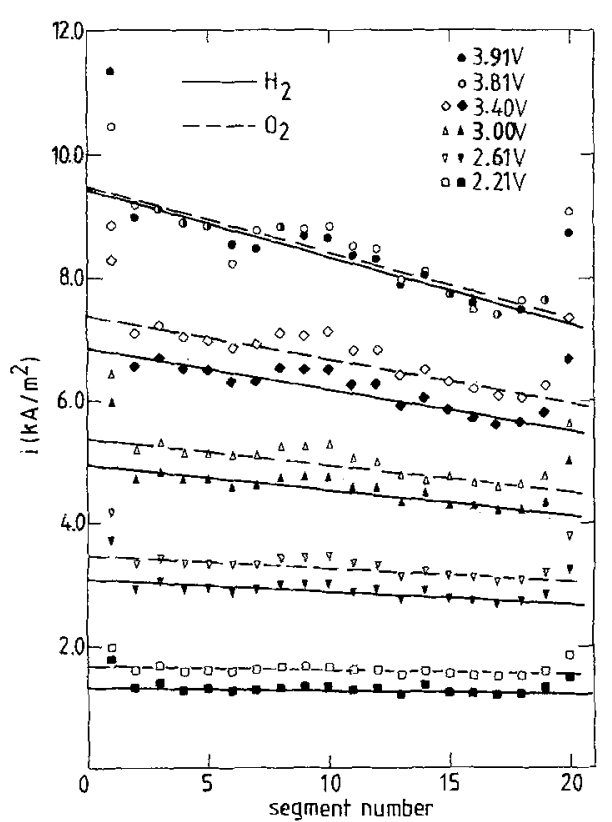

Fig. 6. Current density distributions for oxygen and hydrogen evolution at various current densities and a solution flow velocity of $0.05 \mathrm{~m} \mathrm{~s}^{-1}$. 


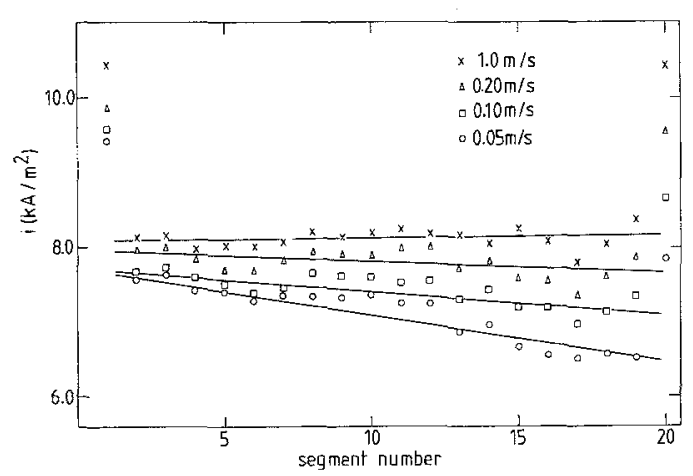

Fig. 7. Current density distribution for hydrogen evolution at various solution flow velocities at a potential of $3.60 \mathrm{~V}$.

constant potential of $3.60 \mathrm{~V}$ between the segments of the working electrode and the counter electrode. At low solution flow velocities the differences in current density between the bottom and the top of the electrode are clearly visible. At solution flow velocities higher than approximately $0.3 \mathrm{~m}$ $\mathrm{s}^{-1}$ the current density becomes constant over the entire electrode, except for the deviations at the bottom and top segments already mentioned. In Fig. 8 the current density distribution in the

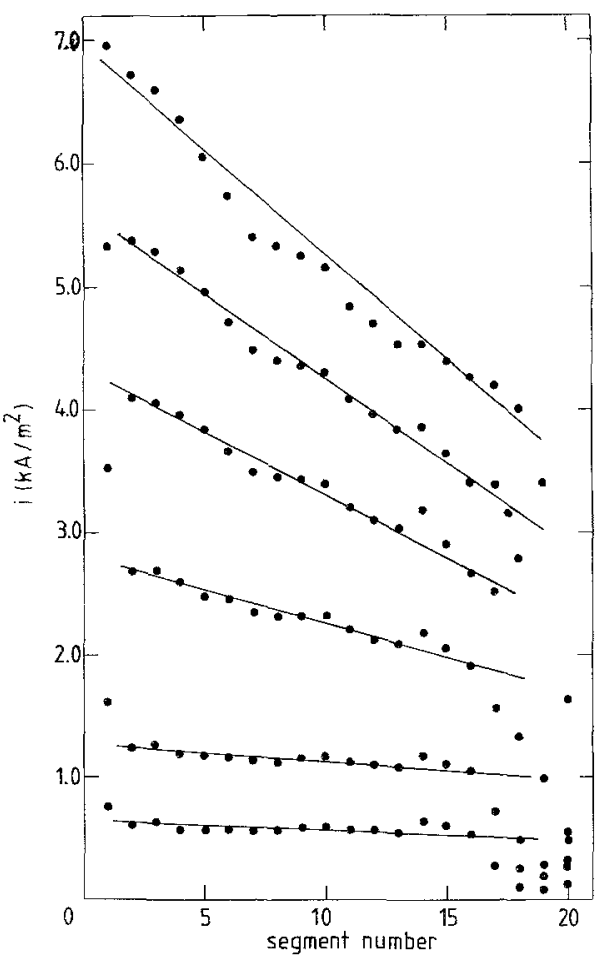

Fig. 8. Current density distributions in the absence of forced convection. absence of forced convection is shown at various cell potentials. The differences in current density between the bottom and the top of the electrode are high, due to the accumulation of bubbles in the upper part of the electrolysis cell. In the absence of forced flow the bubbles rise in the electrolyte, but they can be dragged down in the electrolyte flow induced by rising bubbles. Therefore, the gas holdup in the cell will be very much larger than in the case of even a small applied forced flow through the cell.

\subsubsection{Effect of electrolyte concentration. The} effect of electrolyte concentration has only been studied for hydrogen evolution at the working electrode. In Fig, 9 the current density distribution at potential differences between the working and the counter electrode of 3.9 and $3.0 \mathrm{~V}$ are given for various $\mathrm{KOH}$ concentrations. The differences in current density, relative to the average current density, between the bottom and the top of the electrolysis cell decrease at decreasing concentration.

However, at a constant potential difference between anode and cathode and decreasing electrolyte concentration, the average current density decreases. Since the current density distribution at

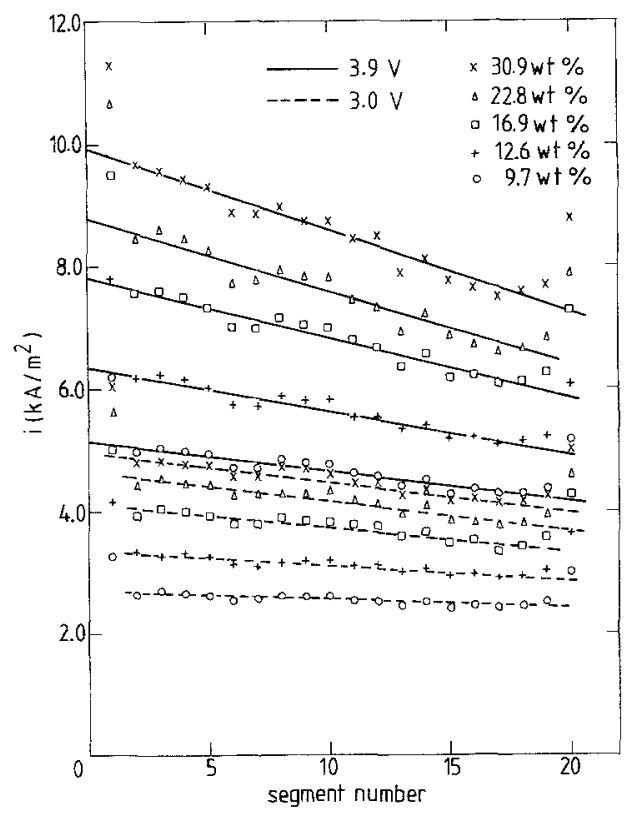

Fig. 9. Current density distribution at potential differences of 3.9 and $3.0 \mathrm{~V}$ for various $\mathrm{KOH}$ concentrations, $v_{l}=$ $0.05 \mathrm{~m} \mathrm{~s}^{-1}$. 
a cell potential difference of $3.0 \mathrm{~V}$ and a $\mathrm{KOH}$ concentration of $30.9 \mathrm{wt} \%$ almost equals the distribution at $3.9 \mathrm{~V}$ and $9.7 \mathrm{wt} \% \mathrm{KOH}$, the effect can be contributed to the simultaneous decrease in average current density. No detectable effect of electrolyte concentration remains.

\subsection{Ohmic resistance}

\subsubsection{Effect of current density. The effect of the} current density on the ohmic resistance in the cell has been studied for hydrogen and oxygen evolution at the working electrode at various solution flow velocities and heights in the electrolysis cell. In Fig. 10 the ohmic resistance between two segments of the hydrogen evolving working electrode, at respective heights of 15 and $35 \mathrm{~cm}$ from the bottom of the electrode and the tips of Luggin capillaries located at a distance of $4 \mathrm{~mm}$ perpendicular to the electrode, is given as a function of current density at various solution flow velocities. From Fig. 10 it follows that, at low solution flow velocities, the ohmic resistance increases at increasing current density. At high solution flow velocities, the ohmic resistance is almost independent of current density.

When the gas production rate is low, namely at low current density, one would expect the resistance of the bubble-electrolyte mixture to approximate the resistance of the pure electrolyte. This is, however, not confirmed by the experimental

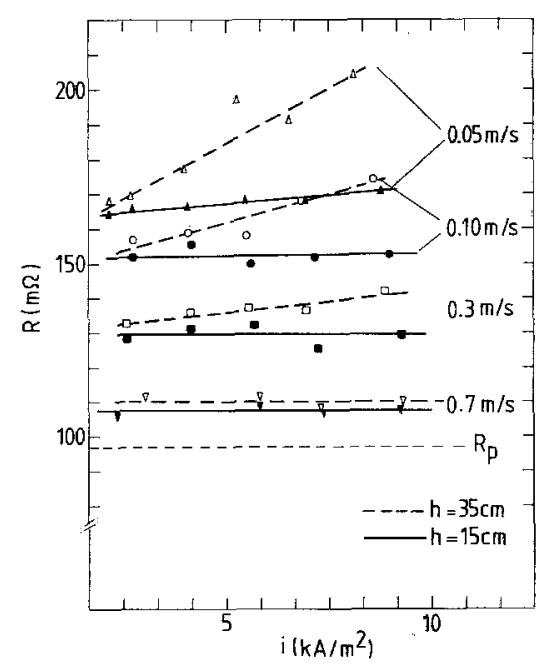

Fig. 10. Ohmic resistance as a function of current density at various solution flow velocities at two heights in the electrolysis cell.

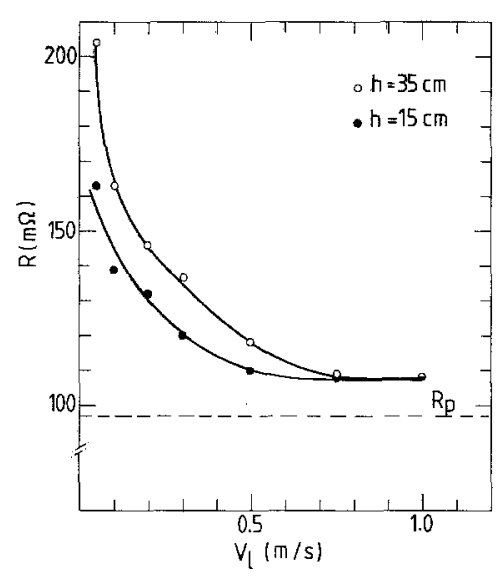

Fig. 11. Ohmic resistance at two heights as a function of solution flow velocity. $E=3.60 \mathrm{~V}$.

results. Especially at low solution flow velocities, the ohmic resistance at low current densities is considerably higher than the resistance of the pure electrolyte. This indicates that the resistance is not simply determined by the rate of gas production. Possibly a crowded bubble layer adjacent to the electrode is formed almost immediately, causing a substantial increase in resistance.

\subsubsection{Effect of solution flow velocity. In Fig. 11} the ohmic resistance between two segments of the working electrode at respective heights of 15 and $35 \mathrm{~cm}$ from the bottom of the working electrode is given as a function of solution flow velocity at a fixed potential difference between the hydrogen evolving working electrode and the counter electrode of 3.6 V. From Fig. 11 it follows that the ohmic resistance decreases with increasing flow velocity. At a solution flow velocity of $1 \mathrm{~m} \mathrm{~s}^{-1}$ the bubbles in the bubble-electrolyte mixture hardly affect the ohmic resistance which approximates the resistance of the pure electrolyte even at high current densities.

3.3.3. Effect of height. An indication of the effect of height on the ohmic resistance variations in the electrolysis cell is obtained from the current density distribution measurements presented in section 3.2. The current density in the cell decreases at increasing height which is to be expected since the gas volume fraction increases with height. Ohmic resistance measurements between segments of the working electrode and Luggin capillaries confirm that the ohmic resistance increases with increasing 
height in the cell, cf. Figs. 10 and 11. The effect is more pronounced at high current densities and low solution flow velocities.

\section{Discussion}

\subsection{Bubble diffusion model}

To a large extent the performance of an electrolytic cell is governed by transport phenomena. Therefore, insight into the flow situation in the reactor is of great importance to model development. A favourite approach is to apply boundary layer theory to the regions adjacent to an electrode.

The common boundary layer equations are, however, simplifications of the Navier-Stokes equations, derived for a surface in contact with an unbounded free stream. In most electrolytic reactors, the flow situation is very different.

The transport of bubbles in the electrolytic cell takes place through the motion of the bubbles relative to and together with the electrolytic flow and through turbulent diffusion. The problem is too complicated to find an exact solution. Therefore, the best approach is to solve a simplified version of the problem first and then gradually extend it to match the real situation as much as possible.

To solve the diffusion problem the following assumptions are made:

Immediately after detachment from the electrode surface, the bubbles attain the steady state velocity.

Quantities are independent of the horizontal coordinate parallel to the electrode.

The channel has smooth walls.

The electrolyte velocity increases linearly with increasing distance to the electrode surface $\left(=\left(\mathrm{d} v_{l}\right)\right.$ $\mathrm{d} x) x$ ) with $\mathrm{d} v_{l} / \mathrm{d} x$ independent of $x$ and proportional to the average flow velocity.

The velocity of the bubbles relative to the electrolyte is negligible, which is acceptable for small bubbles.

The turbulent diffusion coefficient, $K_{\mathrm{T}}$, of the bubbles is uniform in the entire cell.

The number of bubbles generated per unit surface area and unit time, $\psi$, is constant over the entire electrode, $\psi=-K_{\mathrm{T}}(\partial N / \partial x)_{x=0}$ with $N=$ the number of bubbles per unit of volume.

In the stationary case the diffusion equation for
$\mathrm{N}$ reads:

$$
\frac{1}{K_{\mathrm{T}}}\left(\frac{\mathrm{d} v_{l}}{\mathrm{~d} x} x\right) \frac{\partial N}{\partial h}=\frac{\partial^{2} N}{\partial x^{2}}+\frac{\partial^{2} N}{\partial h^{2}}
$$

With boundary conditions:

$$
h<0(\partial N / \partial x)=0
$$

$$
\begin{aligned}
& \text { for } x=0 \\
& \qquad h \geqslant 0(\partial N / \partial x)=-\psi / K_{\mathrm{T}} \\
& \text { for } x \rightarrow \infty \quad(\partial N / \partial x)=0 \\
& \text { for } h<0 \quad N=0
\end{aligned}
$$

Neglecting $\partial^{2} N / \partial h^{2}$, the equation can be solved, yielding:

$$
N=\frac{3 \psi}{K_{\mathrm{T}} \Gamma(1 / 3)} \frac{1}{A} \int_{A x}^{\infty}\{t-A x\} e^{-t^{3}} \mathrm{~d} t
$$

With $A=\left(\frac{\mathrm{d} v_{l} / \mathrm{d} x}{9 K_{\mathrm{T}} h}\right)^{1 / 3}$

The thickness of the bubble layer, $\delta_{\mathrm{T}}$, is assumed small in comparison to the width of the compartment and is taken to equal the $x$-value at the intersection of the tangent to the curve of $N(x, h)$ in $x=0$ and the $x$-axis. Since $(\partial N / \partial x)_{x=0}=-\psi / K_{\mathrm{T}}$ this thickness given by:

$$
\delta_{\mathbf{T}}=\left(\frac{N K_{\mathbf{T}}}{\psi}\right)_{x=0}
$$

The thickness of the bubble layer can now be approximated by:

$$
\delta_{\mathrm{T}}=\left(\frac{K_{\mathrm{T}} h}{\mathrm{~d} v_{l} / \mathrm{d} x}\right)^{1 / 3}
$$

The dependence of the thickness of the bubble layer on height and velocity follows directly from this equation. Its thickness is proportional to $h^{1 / 3}$ and, since it is assumed that $\mathrm{d} v_{l} / \mathrm{d} x$ is proportional to $v_{l}$, it is proportional to $v_{l}^{-1 / 3}$. The dependence of $\delta_{\mathbf{T}}$ on current density cannot, however, be obtained from this equation. It is likely that the generation of bubbles affects the turbulent diffusion coefficient and has a slight effect on the electrolyte velocity gradient. However, no quantitative relations describing these effects are available.

Comparing the obtained theoretical relation to the experimental expression for the thickness of the bubble layer adjacent to the electrode (Equa- 


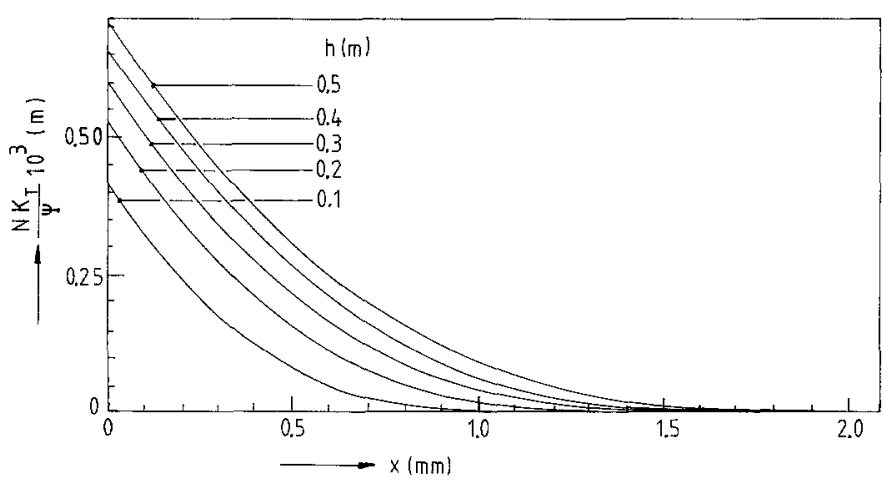

Fig. 12. Bubble density as a function of distance to the electrode surface at various heights. $K_{\mathrm{T}}=3 \times 10^{-7} \mathrm{~m}^{2} \mathrm{~s}^{-1}$. tion 6) it is noted that, for the effect of height, the relations agree well. There is, however, a discrepancy between the relations where the solution flow velocity is concerned, but from both relations it follows that $\delta$ decreases with increasing solution flow velocity.

Substituting the experimentally obtained value $\delta=0.6 \mathrm{~mm}$ at $h=35 \mathrm{~cm}, i=6 \mathrm{kA} \mathrm{m}^{-2}$ and $v_{l}=$ $0.3 \mathrm{~m} \mathrm{~s}^{-1}$ into Equation 10 and assuming a velocity gradient of $500 \mathrm{~s}^{-1}$ for this situation a value for $K_{\mathrm{T}}$ of $3.10^{-7} \mathrm{~m}^{2} \mathrm{~s}^{-1}$ is obtained. In Fig. $12 \mathrm{~N}$ is plotted as a function of $x$ for various heights in the cell for these values of $K_{\mathrm{T}}$ and $\mathrm{d} v_{l} / \mathrm{d} x$. From this figure it follows that the bubble density at $x>$ $1.5 \mathrm{~mm}$ is negligible. Experimentally it is found that the bubbles spread over the entire gap between the electrode and the diaphragm. This may be caused by flow patterns which extend over a relatively large distance, for which the diffusion theory is not applicable. The local bubble density then equals the bubble density due to the diffusion pro- this layer, $f_{\mathrm{b}}$, equals the gas void fraction in the second layer (cf. Fig. 13).

Applying the Bruggeman equation the resistance of the bubble layer is given by:

$$
R_{1}^{\prime \prime}=R_{\mathrm{p}}^{\prime} \int_{0}^{\delta}\left[1-f_{0}+\left(f_{0}-f_{\mathrm{b}}\right) x / \delta\right]^{-3 / 2} \mathrm{~d} x
$$

The gas void fraction in the second region, the rest of the cross-sectional area, $f_{\mathbf{b}}$, is assumed constant over the entire width. Its value is approximated by dividing the volume of gas produced per unit time by the volume of electrolyte flowing through the compartment per unit time and depends on current density, solution flow velocity and height in the electrolysis cell. The resistance of this section is given by:

$$
R_{2}^{\prime \prime}=R_{\mathrm{p}}^{\prime}\left(1-f_{\mathrm{b}}\right)^{-3 / 2}\left(d_{\mathrm{wm}}-\delta\right)
$$

The relative resistance in the electrolysis cell between the working electrode and the diaphragm can then be expressed as:

$$
R / R_{\mathrm{p}}=\frac{\int_{0}^{\delta}\left[1-f_{0}+\left(f_{0}-f_{\mathrm{b}}\right) x / \delta\right]^{-3 / 2} \mathrm{~d} x+\left(1-f_{\mathrm{b}}\right)^{-3 / 2}\left(d_{\mathrm{wm}}-\delta\right)}{d_{\mathrm{wm}}}
$$

cess superposed on the bubble density caused by the long range transport process.

From the aforesaid it follows that two bubble regions can be distinguished. The first region, the bubble layer adjacent to the electrode, is crowded with bubbles and the average solution flow velocity in this layer is relatively low, whilst in the second region the bubble population is much lower and the average solution flow velocity is higher. The gas void fraction in the first layer is assumed to decrease linearly over the width of the layer. The gas void fraction at the electrode surface is denoted by $f_{0}$. The gas void fraction at the boundary of

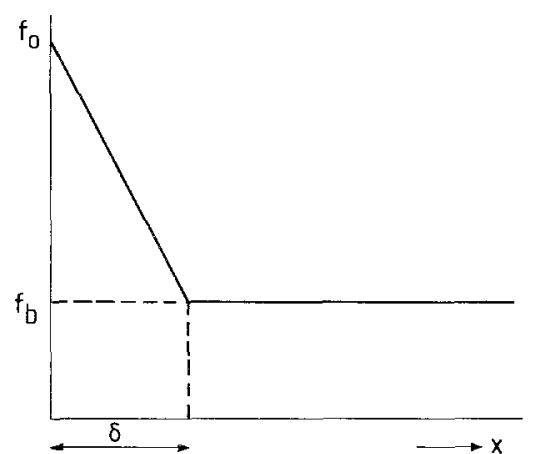

Fig. 13. Assumed gas void distribution perpendicular to the electrode surface. 


\subsection{Verification of the new model}

In Section 4.1 a new model, relating the gas void fraction distribution to the ohmic resistance in the electrolysis cell, is proposed. With this model predictions for the ohmic resistance in the electrolysis cell can be made, provided that the values of $f_{0}, f_{\mathrm{b}}$, $\delta$ and $d_{\mathrm{wm}}$ are known. The value of $d_{\mathrm{wm}}$ follows directly from the experimental set-up and equals $4 \mathrm{~mm}$. The assumed value of $\delta$ follows from measurements in Section 3.1 and is given by Equation 6 .

From measurements by Janssen [9] it follows that, for electrolytically evolved hydrogen and oxygen, only approximately $60 \%$ of the produced gas leaves the electrode in the form of gas bubbles. The rest is carried off in the form of supersaturated electrolyte. The average gas void fraction in the second region, $f_{\mathrm{b}}$, is approximated according to the following equation:

$$
f_{\mathrm{b}}=0.6 \frac{w h i_{\mathrm{av}} V_{\mathrm{M}}}{n F} /\left(V_{l}+0.6 \frac{w h i_{\mathrm{av}} V_{\mathrm{M}}}{n F}\right)
$$

where $w=$ the width of the electrode, $V_{\mathrm{M}}=$ the molar gas volume and $V_{l}=$ the volume of liquid flow per unit time. The void fraction $f_{0}$ is high, but its value is not known. As a first approximation it is assumed independent of current density and height and only slightly dependent on solution flow velocity. It is taken to vary between 0.85 at $v_{l}=0.05 \mathrm{~m} \mathrm{~s}^{-1}$ and 0.60 at $v_{l}=1.0 \mathrm{~m} \mathrm{~s}^{-1}$.

In Fig. 14 the calculated relative resistance is

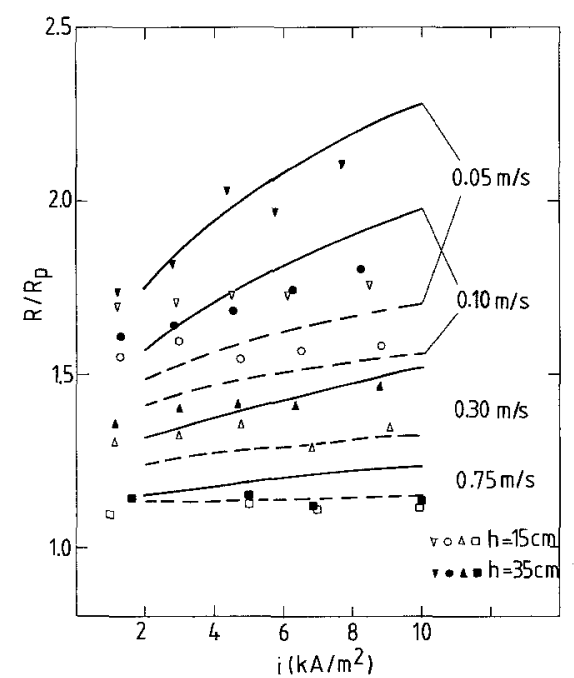

Fig. 14. Calculated and measured relative resistance as a function of current density for various situations. plotted as a function of current density for various situations. The measured values (Section 3.3) are also indicated in the figure.

From Fig. 14 it follows that the qualitative agreement between the predicted and the measured results is relatively good. There are some discrepancies in a quantitative sense, but this is not surprising since the numerical values used to calculate $R / R_{\mathrm{p}}$ are taken rather arbitrarily.

In the approach used, the Bruggeman equation has been applied at very high gas void fractions.

The Bruggeman equation has been derived only for low gas void fractions, where the bubbles do not influence each other. Recently, Janssen [10] found that the Bruggeman equation could be applied to gas bubbles attached to the electrode surface. It is therefore assumed that the range of validity of the equation is much larger than the limited range for which it has been derived.

The effect of the calculated resistance on the current density distribution can only be compared to the experimental current density distribution in a qualitative way, since the calculated resistance is only a part of the total cell resistance which governs the current density distribution. It is obvious that when differences in resistance are large, namely at high current densities and low solution flow velocities, the differences in current density will also be large. This is in agreement with experimental results (cf. Section 3.5.1). Approximating the current density distribution by a straight line, the local current distribution is expressed by the following relation:

$$
i_{\mathrm{h}}=i_{\mathrm{av}}+\left(\frac{H-2 h}{2 H}\right) \Delta i
$$

where $\Delta i=$ the difference in the extrapolated values of $i$ between $h=0$ and $h=H$. In Fig. $15 \Delta i$ is plotted as a function of $i_{\text {av }}$ on a double logarithmic scale for various solution flow velocities. The figure shows straight lines with a slope of approximately 1.6 , independent of solution flow velocity. Therefore, $\Delta i$ can be expressed in dependence on $i_{\text {av }}$ by:

$$
\Delta i=c i_{\mathrm{av}}^{1.6}
$$

where $c$ depends on the solution flow velocity.

A plot of $c_{0}-c$ versus $v_{l}$ on a double logarithmic scale shows a line with a slope of 0.06 with deviations at very low and high solution flow velocities. Therefore, $c$ can be expressed in depend- 


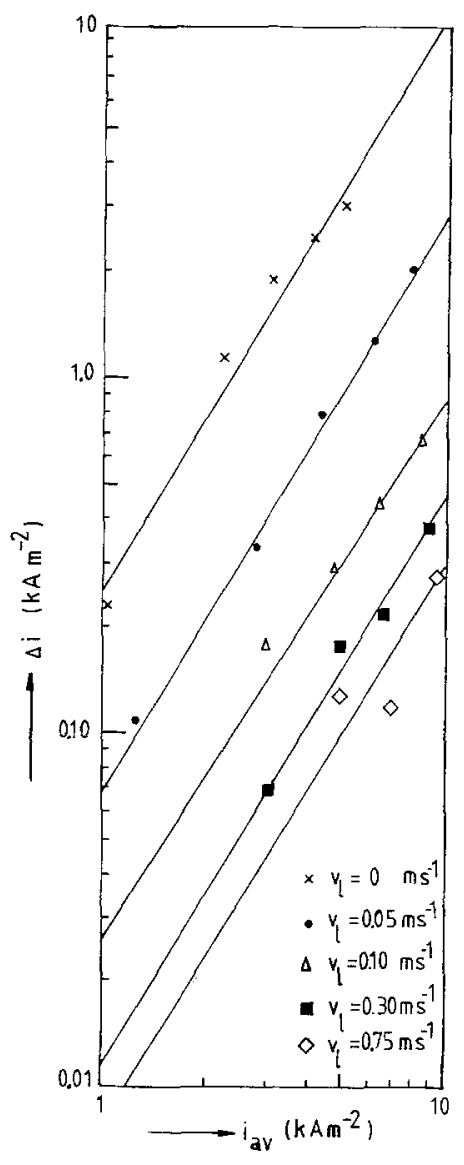

Fig. 15. $\Delta i$ as a function of $i_{\text {av }}$ on a double logarithmic scale for various solution flow velocities.

ence on solution flow velocity by:

$$
c=c_{0}-0.24 v_{l}^{0.06}
$$

with $c_{0}=0.24\left(\mathrm{kA} \mathrm{m}^{-2}\right)^{-0.6}$ dependent on $E$.
Combination of Equations 15 to 17 yields the following empirical expression for the local current density in dependence on $i_{\mathrm{av}}$ and $v_{l}$ :

$i_{\mathrm{h}}=i_{\mathrm{av}}+c_{0}\left(\frac{H-2 h}{2 h}\right)\left[1-\left(v_{l} / v_{l, x}\right)^{0.06}\right] i_{\mathrm{av}}^{1.6}$

It may be concluded that the proposed model can be used satisfactorily as an approximation. Additional research is needed to decide whether the gas void fraction in the layer adjacent to the electrode does indeed decrease linearly with distance or that another profile, e.g. a parabolic profile, describes the decrease in gas voidage better. A small dependence of $f_{\mathbf{b}}$ on distance may be introduced to improve the relation.

\section{References}

[1] C. W. Tobias, J. Electrochem. Soc. 106 (1959) 833.

[2] J. E. Funk and J. F. Thorpe, ibid. 116 (1969) 48.

[3] I. Rousar, ibid. 116 (1969) 676.

[4] Z. Nagy, J. Appl. Electrochem. 6 (1976) 171.

[5] H. Vogt, Electrochim. Acta 26 (1981) 1311.

[6] C. W. M. P. Sillen, PhD Thesis, Eindhoven University of Technology, Eindhoven (1983).

[7] B. E. Bongenaar-Schlenter, PhD Thesis, Eindhoven University of Technology, Eindhoven (1984).

[8] B. E. Bongenaar-Schlenter, L. J. M. Konings, C. J. Smeijers, J. H. G. Verbunt, E. Barendrecht, L. J. J. Janssen, W. M. Sluijter and S. J. D. van Stralen, 'Ohmic potential drop and gas bubble radius distribution in alkaline water electrolysis', Proceedings of the 3rd International Seminar Hydrogen as an Energy Carrier, D. Reidel Publishing Company, Lyon, (1983) p. 206-218.

[9] L. J. J. Janssen and E. Barendrecht, J. Appl. Electrochem. 15 (1985) 549.

[10] L. J. J. Janssen and E. Barendrecht, Electrochim. Acta 28 (1983) 341. 